MANCHESTER

1824

†⿺

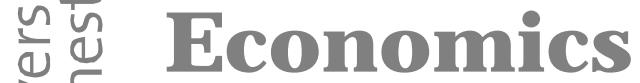

Discussion Paper Series

EDP-1218

\title{
Specification of financial incentives for quality in health care contracts
}

\author{
Eleonora Fichera \\ Hugh Gravelle \\ Mario Pezzino \\ Matt Sutton
}

September 2012

Economics

School of Social Sciences

The University of Manchester

Manchester M13 9PL 


\title{
Specification of financial incentives for quality in health care contracts
}

\author{
Eleonora Fichera ${ }^{a}$, Hugh Gravelle ${ }^{b}$, Mario Pezzino ${ }^{c}$, Matt Sutton ${ }^{*, a}$ \\ ${ }^{a}$ Health Sciences - Economics, School of Community Based Medicine, University of \\ Manchester, UK. \\ ${ }^{b}$ Centre for Health Economics, University of York, UK. \\ ${ }^{c}$ Economics, School of Social Sciences, University of Manchester, UK.
}

\begin{abstract}
We consider how purchasers and providers negotiate the quality element of contracts when the purchasers are required to link a fixed proportion of revenue to quality. A simple model predicts that the complexity of the quality element will depend on purchaser and provider characteristics. Using data extracted from 153 of the 169 contracts for acute hospital services in England in 2010/11, we find that the complexity of the quality element of the contract is determined by the type of provider, whether negotiation was passed to an agency, the regional contractual constraints and whether the provider had teaching status.
\end{abstract}

Keywords:

Quality; financial incentives; pay for performance; Nash bargaining. JEL classification:

I11, I18, L51, C35

\footnotetext{
${ }^{*}$ Corresponding author at: Health Sciences - Economics, School of Community Based Medicine, 1.304 Jean McFarlane Building, University of Manchester, Manchester M13 9PL, UK. Tel.:+44 (0)161 275 5952. Fax:+44 (0)161 2755205.

Email address: matt.sutton@manchester.ac.uk.
} 


\section{Introduction}

Since 1991 the National Health Service in England has been organised as an internal market in which local purchasers negotiate contracts with separate provider organisations. The composition of the purchaser and provider organisations has been reformed repeatedly but the content of the contracts between the parties has evolved more slowly. Until 1997, purchasers and providers had considerable freedom to determine the contractual arrangements that governed their relationship but the principal differentiation of contracts was whether or not payments were dependent on volume (Chalkley and McVicar (Vol. 27, 2008)). From 2003/04, activity-based financing (called Payment by Results) was gradually introduced and providers were reimbursed on a casemix-adjusted tariff determined by the Department of Health and based on the average costs of procedures across all hospitals (Street and Maynard (2007)). Although there was no evidence that quality was adversely affected (Farrar et al. (2009)), the Department of Health became concerned that providers might reduce quality to keep costs below the tariff (Department of Health (2009)). The Commissioning for Quality and Innovation (CQUIN) payment framework was introduced in 2009 requiring commissioners to link payment to measures of quality. By 2011 local purchasers had to make $2.5 \%$ of the contract value conditional on the fulfilment of locally negotiated quality indicators. Purchasers were given considerable autonomy in choosing which aspects of quality to incentivise, which quality indicators to use, and how they were to be linked to payment.

In this paper we examine more than 150 contracts for acute providers in England (about 91\% of providers) from the second year of the CQUIN scheme to determine how the content of local CQUIN schemes varies with the characteristics of providers and purchasers, including their size, the type of provider, their financial positions and the extent to which any provider quality improvements would benefit other purchasers.

Only three papers (Berthiaume et al. (2004); Reiter et al. (2006); Roski

et al. (2003)) have looked at the link between organisational characteristics and adoption of financial incentives for hospital quality improvement. They focus on the U.S. and use a much smaller sample of hospitals than in this paper. They also do not provide any theoretical analysis to support the empirical tests performed. In the U.K., Csaba and Fenn (Vol. 16, 1997) and Chalkley and McVicar (Vol. 27, 2008) have focused on the relation between contract form and provider/purchaser characteristics between 1990 and 1997. 
They examined contracts relating payment to volume of activity and do not consider quality incentives.

This paper contributes to the literatures on contract form and financial incentives for quality improvement in health care. First, we present a simple model of contract choice and use it to motivate the empirical analysis. Second, we test the empirical implications of this model using count data models to determine how the complexity of an incentive scheme is related to provider and purchaser characteristics. For this purpose we have richer information on the characteristics of providers and purchasers than previous studies. We find that the degree of concern for quality and the financial efficiency of the purchaser on one hand, the teaching status of the provider on the other, and the constraints imposed by the regional health authority significantly determine the complexity of the locally-negotiated agreement.

In the next section we explain the contractual arrangements in the NHS and the specific characteristics of the CQUIN scheme. In section 3 we describe the empirical and theoretical literature on contract choice in health care and in other fields of economics. Our theoretical model is in section 4. Section 5 describes our data sets and methods. Descriptive statistics and results are reported in section 6 . Section 7 concludes.

\section{Contractual arrangements in the NHS}

\subsection{The contracting parties}

The organisational structure of the NHS in England has changed repeatedly over the last 60 years. A major change in the last 20 years has been the creation of an internal market, in which the purchaser role has been separated from the provider role. In 2002 the Labour government outlined the new market-based reforms in the document Delivering the NHS Plan: next steps on investment, next steps on reforms (Department of Health (2002)). The plan included two major reforms: patient choice of provider for elective care and the purchasing of healthcare services by a new group of purchasers called Primary Care Trusts (PCTs).

Under the new market reform, secondary and specialist care providers were encouraged to compete to attract individual patients for elective treatment and for contracts. The introduction of Foundation Trust (FT) status was intended further to stimulate competitive quality improvement amongst providers. Upon meeting certain clinical quality and financial standards, hospital trusts could apply to become FTs. As FTs, hospitals would become 
independent, not-for-profit organisations; they would reinvest their profits in services and could access private capital.

The purchasing function in the NHS is organised geographically. In 2010/11 there were 151 PCTs, which are lower-level local health authorities that are primarily responsible for planning, purchasing and securing health services for their local population. They receive a budget based on a weighted capitation formula which reflects the demographic structure, need characteristics of their populations (see Gravelle et al. (2003)) and variations in expected input prices (see Elliott et al. (2009)). These lower-level local health authorities were managed by ten higher-level, regional Strategic Health Authorities (SHAs). These SHAs are the link between the national Department of Health (DH) and the NHS. They are responsible for implementing national policy, monitoring the performance of the local purchasers and the providers that had not achieved FT status, and managing the health care market.

In addition, there are two national regulators. Monitor is the economic regulator of FTs and holds them accountable for the delivery of services. The Care Quality Commission monitors other providers against standards set by the Government through its health policies, National Service Frameworks and clinical guidance provided by the National Institute for Health and Clinical Excellence (NICE).

\subsection{The NHS Standard Contract and the CQUIN scheme}

The process of contracting is the focal point of the split between purchasers and providers. An NHS Standard Contract was introduced in 2007 for acute services to be used for all providers offering services to the NHS. These contracts were legally binding documents between purchasers and providers (see Petsoulas et al. (2011)).

The 2008 DH Report, High Quality Care for All, highlighted a new focus on quality improvement and proposed new arrangements where a proportion of each provider's income was to be linked to quality improvement. This Commissioning for Quality and Innovation (CQUIN) Framework was intended "to support and reinforce other elements of the approach on quality and existing work in the NHS by embedding the focus on improved quality of care in commissioning and contract discussions" (Department of Health (2009) p.5).

Under the CQUIN framework, purchasers and providers are required to contractually link payment to quality improvements. In $2009 / 10,0.5 \%$ of 
contract values were required to be linked to quality improvement. This was mandatory for contracts for acute hospital services and optional for contracts for community, mental health and ambulance services. In this first year it was expected that many organisations would choose to use the framework to focus on data collection, supporting the wider emphasis on measuring for improvement. This involved collecting data to establish the level of baseline performance in areas of care where the purchaser and provider agreed that quality improvement was needed. CQUIN schemes were also used to encourage improvement in the quality of data collected, or help develop metrics for innovation. Where organisations felt they already had good quality data, they could choose to focus on quality improvement from the start.

From 2010/11, all NHS contracts had to include a CQUIN scheme. The proportion of the contract value linked to quality improvement increased to 1.5\%. Each CQUIN scheme in the acute sector had to include two nationallymandated elements on (i) reducing the impact of Venous Thromboembolism (VTE) and (ii) improving Patient Experience. To achieve the VTE national goal, providers had to undertake a VTE risk assessment on at least $90 \%$ of adult inpatients. To achieve the Patient Experience national goal, the proportion of patients reporting that the service was responsive to their needs had to exceed a locally-negotiated threshold. The proportion of contract value linked to these national goals was set nationally by the $\mathrm{DH}$ at $0.3 \%$ for both goals, leaving $1.2 \%$ of revenue to be linked to other quality indicators.

The SHAs could also specify regional elements for CQUIN schemes. Thus, some PCTs could be more constrained in negotiating local quality elements than other purchasers.

Within these constraints, the local elements of the CQUIN scheme were completely flexible and could vary across providers depending on the negotiation process with the purchasers. Unlike the first year, in the second year PCTs were instructed not to pay for data collection. They were advised that outcome measures were preferable, but process indicators could be used if there was a direct link to better outcomes.

For each provider, a single organisation is designated as the negotiating purchaser on behalf of the NHS. This was the Lead or Coordinating PCT or an agency negotiating on behalf of the Lead $\mathrm{PCT}^{1}$. The content of the

\footnotetext{
${ }^{1} \mathrm{An}$ agency is a cluster of PCTs that act as a single purchaser for the provider they lead.
} 
CQUIN scheme was negotiated between the provider and the negotiating purchaser, but achievement of the quality indicators was measured on the activity undertaken by the provider for all purchasers. Guidance on the NHS Standard Contract set out the expectation that the purchaser and the provider would co-operate to reach agreement on the CQUIN scheme with disputes resolved by the SHA. In summary, the negotiating purchaser and provider had to decide a number of elements of the CQUIN scheme:

- the local topics to be included;

- the indicators to be used to measure performance on these local topics;

- the target levels of quality that would represent achievement on the national patient experience goal ${ }^{2}$, and on regional and local indicators;

- the proportion of the up to $1.2 \%$ of revenue ${ }^{3}$ to be attached to achievement of each of the local indicators.

\section{Literature review}

In the theory of the firm, contracts are designed to regulate transactions as well as long-term relations. As pointed out by Coase (1937) and Williamson (1985) (and, amongst others, see Simon (1951); Mayer (1960); Hess (1983)), because of bounded rationality and information failures, the aim of contracts is to reduce transaction costs of the negotiation process. In order to undertake efficient and compatible actions, agents design a mechanism that tells them what to do during the cooperation process and specifies penalties in case such a mechanism is not fulfilled. These requirements can be conceived ex-ante the contract is signed or ex-post during its fulfillment.

It is therefore not surprising that contractual choice has been the focus of the empirical literature in numerous areas, particularly in agriculture, procurement and oil industry. One of the most known examples in agricultural economics is the choice of land tenancy contract. If perfect monitoring were possible, the form of the tenancy contract would not matter as the landlord

\footnotetext{
${ }^{2}$ The target level of quality for the VTE national goal is fixed at $90 \%$.

${ }^{3}$ This is the proportion left after the $0.3 \%$ stipulated for the national goals and any proportion required by the region.
} 
would be able to determine the efficient use of labour regardless of the particular choice of contract. As monitoring is not perfect, the landlord will have to choose a land rental contract. Typically, the literature has compared a fixed rent tenancy, in which a lump-sum is paid by the tenant to the landlord, and sharecropping tenancy, in which a share of the output is paid by the tenant to the landlord as rent. As sharecropping lowers the marginal product of effort, it is known to be a Marshallian inefficient contract compared to fixed-rent. Despite its actual inefficiency had also been shown in empirical studies (see for example Shaban (1987)), sharecropping can still be an equilibrium outcome. An explanation for this tenancy puzzle is that a risk averse tenant is willing to pay a premium to share the uncertainty of the output with the landlord. This is the well-known trade-off between risk and power of the incentive. In the context of the offshore drilling industry, Corts and Singh (2004) find that repeated interactions can mitigate the trade-off between low contracting costs (as in day-rate contracts) and high-powered incentives (as in fixed-price contracts). Their empirical analysis shows that more frequent interactions lead to greater adoption of day-rate contracts mitigating incentive problems. This result is even larger when endogenous matching between drillers and project is taken into account with instrumental variables. Shepard (1993) finds that contractual arrangements between gas stations and oil companies are related to the gas stations characteristics in eastern Massachusetts. He finds that oil companies trade off incentive power for more direct control when observable effort is relatively more important, but choose strong incentives and less direct control when unobservable effort in gas stations is more important. Using data for 277 coal contracts, Joskow (1987) finds that contract duration between buyer and sellers depends on relationship-specific investments as predicted by Williamson (1983).

The analysis of contractual choice in health care is not as developed as in other fields. Indeed, only two papers have dealt with contractual choice in the health service exploiting the local flexibility in contract setting given by the NHS reform in 1990-1997. The first contribution is by Csaba and Fenn (Vol. 16, 1997) who analyse the percentage share of the fixed element in total contracted income for 71 major district acute units representing about a third of acute units in England in the financial year 1992/93. They argue that the choice of cost and volume contracts as opposed to cost per case contracts could be influenced by the trade-off between administration and opportunity costs attached to a possible under utilisation of volume. They show that the fixed element of purchaser-provider contracts depends on the characteristics 
of the negotiating parties ${ }^{4}$. More specifically, they find that excess capacity in relation to purchaser demand as measured by the number of empty bed days reduces the share of the fixed element of the contract. They also find that areas with greater deprivation and a larger share of revenue from private patient care are related to a larger share of the fixed element of the contract. Therefore they argue that capacity constraints and the stochastic nature of patient demand result in purchasers wanting to transfer some risk to local providers by choosing block or cost-volume contracts. The second contribution is by Chalkley and McVicar (Vol. 27, 2008) who consider whether the choice between simple contracts (e.g. block contracts (BC) with a lump sum payment from purchaser to provider) or complex contracts (e.g. sophisticated block contracts (SBC) with a combination of lump sum and extra-payment if costs fall outside of expected range and cost-dependent or volume dependent contracts (VDC) with coverage for a defined limit of patients treated and an agreed rate per case thereafter) is related to provider and purchaser characteristics ${ }^{5}$. They use two datasets. The first contains 236 contracts from 52 purchasers in 1991/92. The second one contains 464 contracts from 106 purchasers in 1993/94. Consistently with the predictions of their theoretical model, they find that contracts for acute services for which there is a significant variation in demand and small variation in costs with low monitoring costs are more likely to entail SBC and VDC. They also find that providers that are more distant from the purchaser are more likely to contract $\mathrm{BC}$ than SBC or VDC because of higher monitoring costs. They find no significant effect of NHS Trust status on the choice of contract.

This paper too focuses on the relation between contractual choice and purchaser/provider (e.g. Principal/Agent) characteristics in a period of large reforms within the NHS. However, the focus is on the characteristics that af-

\footnotetext{
${ }^{4}$ Amongst providers' characteristics they consider the mean number of empty bed days between consultant episodes, the number of people in the provider's district waiting more than one year as a proportion of those treated, unit costs and the percentage of total revenue generated from private patient care. Purchasers' characteristics are the per capita budget and the Jarman underprivileged area score.

${ }^{5}$ Amongst providers' characteristics they consider service type (ie. acute/non acute, mental health or community health, and multiple services), Foundation Trust status and whether the provider is outside of the Health Authority boundary. The only purchaser characteristic is whether the purchaser is a GP. Market structure proxies are the number of providers of similar services within 10 miles and number of GP fundholders per 100,000 population.
} 
fect contractual negotiation based on quality rather than volume.

Principal/Agent models consider the use of incentives by an imperfectly informed principal who tries to induce an agent to provide an efficient level of effort/quality. Quality is usually assumed to be one-dimensional. However, especially in health care, quality is a multi-dimensional variable (see Chalkley and Malcomson (2000)). In Holmstrom and Milgrom (1991) a principal has to fine-tune the use of multiple incentives to induce an agent to apply the right level of multidimensional effort. A well known problem in this type of models is that, depending on the substitutatibility or complementarity between the tasks, increasing the incentive for one task might have a negative effect on the level of effort on the other tasks (see Eggleston (2005), and Kaarbe and Siciliani (2011) for applications of the multitasking framework to health care markets).

Another strand of the literature (motivated in particular by applications related to the use of incentives in health care) ignores the asymmetric information at the heart of the principal/agent model, and studies how financial incentives paid by a third party payer (usually a benevolent regulator) affect quality provision of providers in imperfectly competitive markets (see Calem and Rizzo (1995), Brekke et al. (2006, 2007). Quality is, in general, assumed to be a one-dimensional observable but not contractible variable.

Finally, since negotiations are at the heart of the CQUIN scheme, our paper is related to contributions in the literature that study bargaining between a purchaser (i.e. an insurer) and one (or more) health care provider ${ }^{6}$. In particular Barros and Martinez-Giralt (2008) consider the purchaser's choice of the negotiation mechanism. The authors consider the choice between simultaneous (Nash) bargaining with two different providers and Any Willing Provider, $A W P$, mechanism, where the purchaser offers a contract and providers are allowed to accept it. The authors show that $A W P$ is preferred by the payer when the surplus to be shared is sufficiently high. Siciliani and Stanciol (2008) consider the case in which the payer and the provider can bargain over the price, over the level of activity or simultaneously negotiate over price and activity level. The authors show that a purchaser will prefer to negotiate on both price and activity only when she has a sufficiently high bargaining power. Otherwise it would be counterproductive for the purchaser to negotiate on multiple instruments.

\footnotetext{
${ }^{6}$ See Barros and Martinez-Giralt (2011) for a review of the literature.
} 
Our paper considers the strategic considerations behind the definition of the CQUIN scheme. Specifically we examine how the characteristics of health care providers and purchasers determine the negotiation of the quality content of these contracts. Unlike the scarce literature on this topic, we provide a theoretical representation of the CQUIN structure. Our bargaining model contains aspects in common both with the multitasking models (e.g. the payer in our model can choose between two different incentives to induce the provider to offer quality) and the contributions with observable but not contractible quality (we will assume indeed that the payer can observe quality, but she can induce the provider to supply quality only via the use of financial incentives). Similar to Siciliani and Stanciol (2008) we consider negotiations over two dimensions. However, since our focus is the study of CQUIN bargaining, prices and activity levels are exogenously determined. We will study instead the negotiations over the complexity of the CQUIN part of the contract and the financial quality-related incentives.

We empirically test the implications of this model with a relatively large sample of contracts in an observational dataset. As in Chalkley and McVicar (Vol. 27, 2008) we consider a period in which NHS reforms have pushed towards a more flexible contractual setting. We consider a larger variety of characteristics both on the provider and purchaser side. We also focus on the complexity of contractual choice for quality improvement rather than volume of services.

\section{Theoretical analysis}

The bargaining model described in this section captures some of the strategic considerations behind the definition and structure of the CQUIN scheme.

\subsection{The model}

The model assumes healthcare to be supplied by an acute care provider serving a representative patient who requires a given volume of service. The service is free of charge for the patient and the provider receives payment (as defined in the national contract) from a third party purchaser ${ }^{7}$ (the local

\footnotetext{
${ }^{7}$ The scheme includes the possibility that contracts might be defined at different levels (e.g. national regulator, regional authority, local purchaser). The purchaser takes the quality indicators specified by the national regulator or regional authority.
} 
purchaser). The purchaser has an objective function which is strictly increasing in the quality chosen by the provider. Quality has two aspects. $q_{0} \geq 0$ represents the dimension of quality incentivised at regional level while $n \geq 0$ is the quality directly incentivised by the local purchaser.

In line with the empirical analysis and leaving aside the discrete nature of the problem, $n$ could be interpreted as the number of local quality dimensions that the purchaser intends to incentivise in the contract $^{8}$. Qualities in the CQUIN scheme are incentivised according to a system of targets negotiated by the purchaser and the provider. The purchaser however faces a budget constraint: the amount of money that can be offered to incentivise targeted quality is a fixed portion of the value of the contract.

The purchaser has the objective function

$$
V(n, R ; \cdot)=\alpha B(n ; \cdot)-g\left(p x+R_{0}+R\right)-m(n), \quad g^{\prime}>0, g^{\prime \prime}>0
$$

$x>0$ is the fixed volume of output of the provider for which it is paid the nationally fixed price of $p . B\left(n ; x, q_{0}\right)$ is the social benefit from $x$ units of output with quality $q_{0}, n$ and $\alpha \in(0,1]$ is a parameter that measures how much the purchaser is concerned with the provision of quality care ${ }^{9} . R_{0}$ is the amount to be paid to the provider to be induced to produce regionally mandated quality $q_{0} . R_{0}$ and $q_{0}$ are defined at regional level and are therefore treated as parameters by the purchaser. $m(n)$ is a (strictly increasing and convex) function of $n$ and represents the monitoring costs of the purchaser. $R$ represents the extra cost incurred by the provider to offer a strictly positive level of local quality $n . g\left(p x+R_{0}+R\right)$ represents the opportunity cost incurred by the purchaser who incentivises quality $n$. Suppose that the marginal opportunity cost of payments to the provider by the purchaser is not constant but increasing because the activities forgone in, say, primary care which are also financed by the purchaser are increasingly valuable. We

\footnotetext{
${ }^{8}$ The focus of the number of quality dimensions is required by the nature of the data where we cannot measure the content of each contract (see subsection 5.1 for more details).

${ }^{9}$ Notice that $\alpha$ weights $B$ relative to the purchaser's expenditure on hospital care and on the scheme. The purchaser cares about the financial implications because expenditure on hospitals has an opportunity cost (either in terms of less funding for managerial salaries or because the purchaser has other socially useful things to spend its budget on). The weight will plausibly be lower if the purchaser has a smaller overall budget from the resource allocation process.
} 
assume that the benefits of additional quality indicators are always greater than the effort costs of monitoring so that $V_{n}=\alpha B_{n}-m_{n}$ is always positive ${ }^{10}$. We assume that $V$ is concave in $n$ so that $\alpha B_{n n}-m_{n n}<0$.

Provider utility is

$$
U(n, R ; \cdot)=\pi(n, R ; \cdot)+\delta B(n ; \cdot)=p x+R_{0}+R-\vartheta c(n ; \cdot)+\delta B(n ; \cdot)
$$

The provider's costs to produce quality, $c=\vartheta c\left(n ; x, q_{0}\right)$, depend on the volume of output, the dimensions of quality and a cost shifter (efficiency) parameter $\vartheta>0$. Assume that $c_{n}^{\prime}>0, c_{n}^{\prime \prime}>0, c_{x}^{\prime}>0 . \delta \in[0,1]$ represents the degree of concern for quality of the provider and $p$ is the price per unit of care.

The parties bargain over the complexity of the contract, captured by the number of incentivised indicators $n$ and the discretionary purchaser incentive payment $R$. In line with the CQUIN scheme, we assume that the bargain is constrained by the requirement that total payments cannot exceed a proportion of the exogenously determined payment for volume

$$
k p x-R_{0}-R \geq 0
$$

where $k \in(0,1)$ and by the constraint that the provider cannot make a loss

$$
p x+R_{0}+R-\vartheta c(n ; \cdot) \geq 0
$$

We assume that in the event of failure to agree both parties have zero utility and that the bargain on $n$ and $R$ is the Nash bargaining solution of

$$
\max _{n, R} V(n, R ; \cdot)^{\beta} U(n, R ; \cdot)^{1-\beta}
$$

subject to the two constraints. $\beta \in[0,1]$ is the bargaining power parameter.

The first order conditions are

$$
\begin{array}{ll}
V_{n} \beta V^{\beta-1} U^{1-\beta}+U_{n}(1-\beta) V^{\beta} U^{-\beta}-\lambda_{2} c_{n}(n ; \cdot) \geq 0, & n \geq 0 \\
V_{R} \beta V^{\beta-1} U^{1-\beta}+U_{R}(1-\beta) V^{\beta} U^{-\beta}-\lambda_{1}+\lambda_{2} \geq 0, & R \geq 0
\end{array}
$$

\footnotetext{
${ }^{10}$ This rules out solutions where the provider is paid to achieve fewer quality indicators than she would provide if remuneration did not vary with $n$.
} 
with complementary slackness, plus the two constraints with the complementary slackness conditions on $\lambda_{1} \geq 0, \lambda_{2} \geq 0$.

The efficient set of (interior) contracts is defined by

$$
\begin{aligned}
0 & =V_{n} U_{R}-U_{n} V_{R} \\
& =\left(\alpha B_{n}-m_{n}\right)+\left(\delta B_{n}-\vartheta c_{n}\right) g^{\prime}\left(p x+R_{0}+R\right) \\
& =F(n ; \cdot)
\end{aligned}
$$

and so the slope of the contract curve is

$$
\frac{d R}{d n}=-\frac{F_{n}}{F_{R}}<0
$$

(We have assumed that $\alpha B_{n}-m_{n}>0$ and $g^{\prime}>0$, so the condition defining the contract curve (8) implies that $\delta B_{n}-c_{n}<0$. Hence the denominator in (9) is positive.) The specific (interior) solution of the bargaining problem will be defined by the intersection of the implicit function $F(n ; \cdot)$ and the function, say $G(n ; \cdot)$ implicitly defined by one of the first order conditions as follows.

$$
\begin{aligned}
0 & =V_{R}^{\prime} \beta V^{\beta-1} U^{1-\beta}+U_{R}^{\prime}(1-\beta) V^{\beta} U^{-\beta} \\
& =G(n ; \cdot)
\end{aligned}
$$

The slope of the $G$ curve is

$$
\frac{d R}{d n}=-\frac{G_{n}^{\prime}}{G_{R}^{\prime}}>0
$$

Figure 1 illustrates. The bargain is efficient and so the purchaser and provider indifference curves are tangent. The negative sloped contract curve implies that the contract that yields higher $n$ will generate greater purchaser utility and lower $R$. The intersection between the $G$ and $F$ curves defines the optimal solution.

If one of the parties has all the bargaining power one of the constraints, 3 if $\beta=0$ or 4 if $\beta=1$, will be binding.

If all the bargaining power resides with the provider, i.e. $\beta=0$, then the 


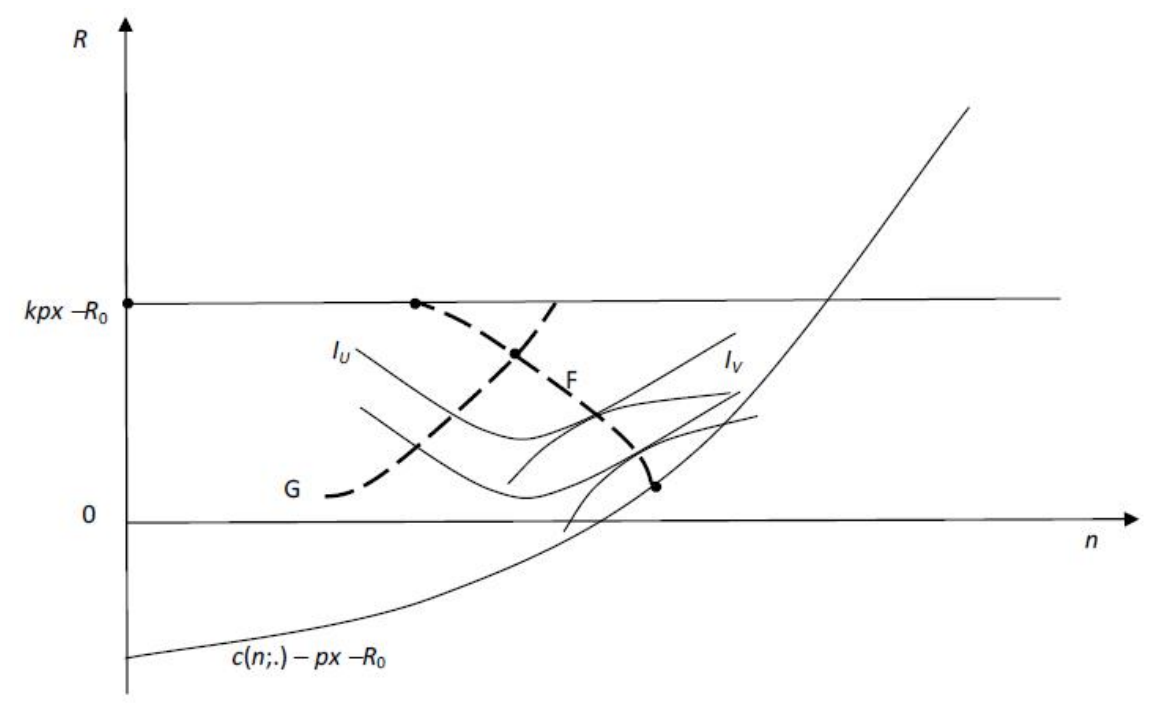

Figure 1: Bargaining solution with increasing marginal cost of purchaser incentive payments. With higher payment $R$ the opportunity cost of other activities forgone is greater and so the purchaser indifference curves is flatter at given complexity $n$. The efficient set of contracts $F$ is negatively sloped and the degree of complexity depends on relative bargaining power as described by $G$.

corner solution is given by $\lambda_{1}=1, \lambda_{2}=0$ and

$$
\begin{array}{r}
k p x-R-R_{0}=0 \\
U_{n}^{\prime}=0
\end{array}
$$

If instead all the bargaining power resides with the provider, i.e. $\beta=1$, then the corner solution is given by $\lambda_{1}=0, \lambda_{2}>0$ and

$$
\begin{array}{r}
-\lambda_{2} \vartheta c_{n}^{\prime}=0 \\
p x+R+R_{0}-\vartheta c=0
\end{array}
$$

\subsection{Comparative statics}

Let us focus our attention to set of interior solutions of the problem in 5, where $\lambda_{1}=\lambda_{2}=0$ and $n>0, R>0$. Simple comparative statics analysis ${ }^{11}$ produces the testable implications considered in section 5. Specifically, the characteristics of the payer and the provider affects the solution to problem

\footnotetext{
${ }^{11}$ The mathematical derivations are described in the appendix.
} 
as follows.

Table 1: Comparative statics analysis on the interior solution

\begin{tabular}{ll}
\hline$\frac{d n}{d \beta}>0$ & $\frac{d n}{d \alpha}>0$ if $\frac{G_{\alpha}^{\prime}}{F_{\alpha}^{\prime}}>\frac{G_{R}^{\prime}}{F_{R}^{\prime}}$ \\
$\frac{d n}{d \delta}>0$ & $\frac{d n}{d \vartheta}<0$ \\
$\frac{d n}{d p}$ if $\frac{G_{p}^{\prime}}{G_{R}^{\prime}}>x$ & $\frac{d n}{d x}$ if $\frac{G_{x}^{\prime}}{F_{x}^{\prime}}>\frac{G_{R}^{\prime}}{F_{R}^{\prime}}$ \\
$\frac{d n}{d q_{0}}>0$ if $\frac{G_{x}^{\prime}}{F_{x}^{\prime}}>\frac{G_{R}^{\prime}}{F_{R}^{\prime}}$ & $\frac{d n}{d R_{0}}=\frac{d n}{d k}=0$ \\
\hline
\end{tabular}

The complexity of the contract, $n$, increases with $\beta$. Intuitively, an increase in $\beta$ gives greater bargaining power to the purchaser. This translates into a right downward shift of the $G$ curve and, since the $F$ curve is unaffected by a change in $\beta$, it produces higher $n$ (and lower $R$ ).

An increase in $\alpha$ has two opposite effects on $n$. It shifts the $F$ curve to the right $\left(-\frac{F_{\alpha}^{\prime}}{F_{n}^{\prime}}>0\right)$ and the $G$ curve to the left $\left(-\frac{G_{\alpha}^{\prime}}{G_{n}^{\prime}}<0\right)$. While clear an increase in $\alpha$ has an unambiguous positive effect on $R, n$ will increase only if the effect of the shift in the $F$ curve more than offsets the shift in the $G$ curve.

An increase in $\delta(\vartheta)$ shifts to the right (left) both curves in figure 1, unambiguously increasing (decreasing) the level of quality $n$.

A higher regionally mandated quality, $q_{0}$ can produce shifts in either direction for both curves. A sufficient condition that would ensure that $d n / d q_{0}>0$ would be both curves moving to the right. The condition would be satisfied if ... has a positive effect on the optimal level of $n$ if the increase in the marginal benefit of $n$, i.e. $\left.\alpha+\delta g^{\prime}\right) B_{n q_{0}}^{\prime \prime}$, is larger than the increase in the marginal costs of provision ${ }^{12}$, i.e. $g^{\prime} \vartheta c_{n q_{0}}^{\prime \prime}$.

An increase in $R_{0}$, the financial incentive defined at regional level, or $k$ have no effect of on the negotiated value of $n$. An increase in $R_{0}$ shifts $F$ to the left and $G$ to the left, nullifying any effect of the equilibrium. $k$ leaves $F$ and $G$ unchanged,since we are focusing on interior solutions.

The effect of on increase in $x$ is ambiguous. Similar to $q_{0}$, it can produce shifts in either direction for both curves. A sufficient condition for $d n / d x$ could be positive is .

The comparative static analysis on the solutions with binding constraint

\footnotetext{
${ }^{12}$ Notice that $c_{n q_{0}}^{\prime \prime}$ might be negative if $q_{0}$ has some form of complementarity with the production of $n$.
} 
produces the following results.

- If $\beta=0$, then

$$
\begin{aligned}
& \frac{d n}{d \alpha}=0=\frac{d n}{d R_{0}}=\frac{d n}{d k}=\frac{d n}{d p} \\
& \frac{d n}{d \delta}>0 \\
& \frac{d n}{d \vartheta}<0 \\
& \frac{d n}{d q_{0}}>0 \text { if }\left(\delta B_{n q_{0}}^{\prime \prime}>\vartheta c_{n q_{0}}^{\prime \prime}\right) \\
& \frac{d n}{d x}>0 \text { if }\left(\delta B_{n x}^{\prime \prime}>\vartheta c_{n x}^{\prime \prime}\right)
\end{aligned}
$$

- If $\beta=1$, then

$$
\begin{aligned}
& \frac{d n}{d \alpha}=0=\frac{d n}{d \delta}=\frac{d n}{d R_{0}}=\frac{d n}{d k}=\frac{d n}{d p} \\
& \frac{d n}{d \vartheta}<0 \\
& \frac{d n}{d q_{0}}>0 \text { if } c_{n q_{0}}^{\prime \prime}<0 \\
& \frac{d n}{d x}=>0 \text { if } c_{n x}^{\prime \prime}<0
\end{aligned}
$$

\subsection{Testable implications}

There are four main testable implications from our theoretical model:

i. The effect of a variation of the purchaser and provider's concern about the locally negotiated quality contracts (i.e. $\frac{d n}{d \alpha}$ and $\frac{d n}{d \delta}$ ); the theoretical model indicates that $\alpha$ and $\delta$ might have a positive effect on locally negotiated qualities when the CQUIN constraint is not binding ( $\delta$ in addition increases $n$ if all the bargaining power is in the hands of the provider).

ii. The effect of a variation in the provider's efficiency on the locally negotiated quality contracts (i.e. $\left.\frac{d n}{d \vartheta}\right)$; the theoretical model indicates that 
higher provider efficiency (i.e. lower $\vartheta$ ) will make it less expensive for the purchaser to incentivise quality $n$ and consequently that a decrease of $\vartheta$ would increase $n$.

iii. The effect of a variation in the provider's size on the locally negotiated quality contracts (i.e. $\frac{d n}{d x}$ ); an increase in output has a positive effect on local qualities if increase in the marginal benefit for the purchaser (measured by $\alpha B_{n x}^{\prime \prime}+g^{\prime}\left(\delta B_{n x}^{\prime \prime}-\vartheta c_{n x}^{\prime \prime}\right)$ ) is larger than the increase in purchasers' opportunity cost and provider's costs to produce a certain level of $n$ (measured by $g^{\prime \prime} p\left(\delta B_{n}^{\prime}-\vartheta c_{n}^{\prime \prime}\right)$.

iv. The effect of a variation in the quality contracts mandated by the regional authority on the locally negotiated quality contracts (i.e. $\frac{d n}{d q_{0}}$ ). The analysis above indicates that the quality mandated by the regional authority has a positive effect on the locally negotiated qualities if the increase in the marginal benefit of $n$ (i.e. $\left.\alpha+\delta g^{\prime}\right) B_{n q_{0}}^{\prime \prime}>g^{\prime} \vartheta c_{n q_{0}}^{\prime \prime}$ ) is greater than the increase in the marginal costs of provision (i.e. $g^{\prime} \vartheta c_{n q_{0}}^{\prime \prime}$ ).

\section{Data and methods}

\subsection{Data sources}

Information on the CQUIN schemes specified for each provider was obtained from the NHS Institute for Innovation and Improvement website (see NHS). We analyse data on the second year, 2010/11, of the CQUIN and focus on NHS acute providers because only the contracts for these providers have been required to link quality to payments since the start of the CQUIN scheme.

The CQUIN schemes are specified as topics (e.g. stroke) and, within topics, specific indicators (e.g. proportion of stroke patients treated on a dedicated stroke unit). The schemes define whether the indicator was for outcome or process improvement, and whether the indicator was nationallymandated, regionally-mandated or locally-negotiated.

We analyse two proxies for complexity (i.e. $n$ in the theoretical model) of the CQUIN contract scheme. First, the numbers of locally negotiated topics and second the number of indicators measuring outcome or process improvement. The free-text nature of the dataset precludes analysis of complexity beyond the number of topics that are required to be monitored and the types

of indicators either for outcome or process quality improvement. Outcome is a measure of complexity as it is more risky for the provider and more costly 
for the purchaser to monitor. The complexity of the contracts is also proxied by the number of topics because as the number of clinical areas increase so do the costs of monitoring performance and of achieving the targets on a larger set of activities.

We link these data sets to characteristics of the provider and the purchaser. On the provider side, we consider the following characteristics. First, the size of an acute provider as measured by the volume of patients treated in 2009/10 (i.e. the parameter $x$ in the theoretical model) proxies for the scale of health services it is able to deliver. It is likely that purchasers will negotiate more topics with larger providers to reflect the quantity of their activity.

Second, teaching and specialist status are proxies for scope of health services. Teaching hospitals have wider scope, including producing education and centres for innovative care. As a result, providers may be willing to negotiate more complex contracts should they be able to exploit economies of scope.

Third, we measure efficiency of the providers (i.e. the parameter $\vartheta$ in the theoretical model) by the Care Quality Commission's (CQC) quality and financial rating and the reference cost index. We obtain the CQC rating of the providers from their "Annual Health Check" in 2008/09. The CQC classifies providers by their quality of care and financial management. Both the CQC quality and financial rating measure whether a provider scored fairly or weakly as opposed to good or excellent. The reference cost index is a measure of how the providers local costs compare to national average costs. It is adjusted for variations in case-mix using the NHS equivalent of Diagnostic Related Groups (DRGs), called Healthcare Resource Groups (HRGs), and variations in expected input prices using the Market Forces Factor. More efficient providers might be willing to negotiate more complex contracts to increase the chances of meeting more targets.

Finally, we consider Foundation Trusts status up to 2009 as authorised by Monitor. As FTs are more independent in that they are allowed to distribute their profits to health services, they might be more concerned about quality than standard providers and they might negotiate more complex contracts (i.e. the parameter $\delta$ in the theoretical model).

On the purchaser side, we proxy the concern for quality (i.e. the parameter $\alpha$ in the theoretical model) by the ratings from the World Class Commissioning (WCC) process, the mean length of waiting time patients have waited in 2009/10, the distance from target (DFT) and the disability- 
free life expectancy (DFLE) measures. The purchaser's ratings are taken from the WCC programme, a commissioning assurance system launched in 2007 which contained an annual review of each purchaser's progress towards achieving better health outcomes, competencies and governance. We use the 2009/10 score to measure the financial position of the lead purchaser. The score is measured on a scale $0-1$ with one being the highest score. The DFT and the DFLE are measured at the start of the 2010 financial year. Both measures are obtained from the 2010/11 Exposition Book. The purchaser's financial position is measured by the extent to which its annual allocation differs from that which it is indicated to need by the national weighted capitation formula. Intuitively, a more cash-strapped purchaser might prefer a more complex quality contract to increase their chances to save money or they might prefer a simple scheme to reduce their monitoring costs. The population's health is measured by DFLE. This is a summary measure used in the monitoring of geographical health inequalities. Purchasers with a worse population health should care more about quality and negotiate more complex CQUIN schemes. Conversely, purchasers with a better population health negotiate simpler CQUIN schemes.

We use the financial relationship between the purchaser and the provider as proxies for the bargaining power of the parties (i.e. $\beta$ in the theoretical model). We use the Purchaser-Provider Matrix available from the DH Exposition Book 2009/10 to calculate the total income the provider receives from the lead purchaser and the proportion of the purchaser's total expenditure on acute services that was paid to this provider (i.e. the bargaining power of the provider and the purchaser, respectively). The bargaining power of the purchaser is proxied by the following additional variables: the proportion of the purchaser's expenditure that is provided by this provider; and an indicator as to whether the lead purchaser/commissioner is part of a cluster or agency. Agencies are more competent at negotiation but less sensitive to the purchaser's preferences. Purchasers will have a higher bargaining power if more of their expenditure goes to the provider with whom they are negotiating a contract.

Finally, some providers will be more constrained than others if their CQUIN scheme has to include a number of topics mandated by the SHA (i.e. $q_{0}$ in the theoretical model).

Table 2 displays a summary of the parameters in the theoretical model and the likely testable effects with their correspondent proxies in the empirical model. 
Table 2: Summary table of the parameters in the theoretical and empirical models

\begin{tabular}{|c|c|c|}
\hline $\begin{array}{l}\text { Parameters in the } \\
\text { theoretical model }\end{array}$ & Testable effects & $\begin{array}{l}\text { Proxy in the } \\
\text { empirical model }\end{array}$ \\
\hline $\begin{array}{l}n=\text { complexity of quality } \\
\text { dimensions }\end{array}$ & $\begin{array}{l}\text { N/A as decision } \\
\text { variable }\end{array}$ & $\begin{array}{l}\text { No. local topics; } \\
\text { No. local outcome indicators; } \\
\text { No. local process indicators. }\end{array}$ \\
\hline $\begin{array}{l}q_{0}=\text { quality dimension incentivised } \\
\text { at regional level }\end{array}$ & $\left(d n / d q_{0}\right)>0$ & $\begin{array}{l}\text { No. region topics; } \\
\text { No. region outcome indicators; } \\
\text { No. region process indicators. }\end{array}$ \\
\hline$x=$ provider's size & $(d n / d x)>0$ & Volume of patients treated. \\
\hline$\vartheta=$ provider's efficiency & $(d n / d \vartheta)<0$ & $\begin{array}{l}\text { CQC finance \& quality scores; } \\
\text { Reference cost-index. }\end{array}$ \\
\hline $\begin{array}{l}\delta=\text { provider's concern about } \\
\text { quality }\end{array}$ & $(d n / d \delta)>0$ & Foundation Trust status. \\
\hline $\begin{array}{l}\alpha=\text { Purchaser's concern about } \\
\text { quality }\end{array}$ & $(d n / d \alpha)>0$ & $\begin{array}{l}\text { Rating of purchaser's financial } \\
\text { governance; } \\
\text { Purchaser's DFT; } \\
\text { Purchaser's population health; } \\
\text { Mean length of waiting time. }\end{array}$ \\
\hline$\beta=$ bargaining power & $\begin{array}{l}\text { determines which } \\
\text { constraints } \\
\text { are binding }\end{array}$ & $\begin{array}{l}\text { Share of provider expenditure } \\
\text { from lead purchaser; } \\
\text { Share of purchaser expenditure at this } \\
\text { provider; } \\
\text { Contract negotiated by an agency for } \\
\text { the purchaser. }\end{array}$ \\
\hline
\end{tabular}

\subsection{Econometric methods}

The complexity of the CQUIN scheme is measured by the number of the topics negotiated locally and by the number of locally-negotiated outcome indicators and process indicators. We use two count data models, namely the generalised linear model (GLM) Poisson and the negative binomial regression. We graphically compare the distribution of the data for each measure of complexity with the Poisson and negative binomial distributions and choose the most appropriate model accordingly ${ }^{13}$.

The standard Poisson regression assumes that $n$, the number of topics or of indicator types, given a set of covariates $x \equiv\left(x_{1}, \ldots, x_{n}\right)$ has a Poisson distribution (Sayyad (1973); Maddala (1986)). The density of $n$ given $x$ is determined by the conditional mean $\mu \equiv E(q \mid x)$ :

$$
f(n \mid x)=\frac{\exp [-\mu(x)]\left[\mu(x)^{n}\right]}{n !} \quad n=0,1, \ldots, N
$$

\footnotetext{
${ }^{13}$ See section 6 for the results of the chosen model. Additional models and specifications together with the plotted distributions are available in Appendix B.
} 
where maximum likelihood estimation is possible given a parameterisation of the conditional mean such as $\mu=\exp (x \beta)$ and a random sample.

Since the basic assumption of variance-mean equality in the Poisson model is rejected for all our dependent variables, we use the following assumption:

$$
\operatorname{Var}(n \mid x)=\sigma^{2} E(n \mid x)
$$

where $\sigma^{2}>0$ is the variance-mean ratio. This is used in the GLM and is called the Poisson GLM variance assumption (Wooldridge (2001)). Overdispersion occurs whenever $\sigma^{2}>1$ as in the case of our analysis.

We scale the standard errors for over-dispersion using the square root of Pearson $\chi^{2}$-dispersion and we show that the results are not dissimilar from the negative binomial ones.

The negative binomial is a popular alternative to the Poisson in case of over-dispersion because it defines the following variance:

$$
\operatorname{Var}(n \mid x)=E(n \mid x)+\alpha[E(n \mid x)]^{2}
$$

with $\alpha \geq 0$ so that under-dispersion is ruled out.

The coefficients of the model are expressed in terms of incidence rate ratios. The parameter estimate of the count models can be expressed as:

$$
\beta=\log \left(\mu_{x+1}\right)-\log \left(\mu_{x}\right)=\log \left(\frac{\mu_{x+1}}{\mu_{x}}\right)
$$

where $\beta$ is the regression coefficient that can be written as the ratio of the expected count, $\mu$, and the subscripts represent the predictor variable evaluated at $x$ and $x+1$.

The likelihood ratio test for over-dispersion is a test of the parameter $\alpha$. Under the null hypothesis, the Poisson and the negative binomial are the same, that is, $H_{0}: \alpha=0$. Under the alternative hypothesis, $H_{1}: \alpha>0$, there is over-dispersion (Cameron and Trivedi (1998)).

Two models have been estimated for each measure of complexity. First we estimate a model containing all variables, then we sequentially delete the least significant variables until a parsimonious model containing only variables statistically significant in the first model is reached. For comparability purposes, the models of outcome and process indicators include the same covariates. 


\section{Descriptive statistics and results}

\subsection{Descriptive statistics}

There are 169 acute providers in England (CQC (2005-2009)). We analyse data for 153 acute providers, representing $91 \%$ of all acute providers in England ${ }^{14}$.

Table 3 shows that on average the number of regionally mandated topics and outcome/process indicators is about three. Locally negotiated contracts contain, on average, about five topics or clinical areas. On average, locally negotiated contracts contain more process than outcome indicators. This is not surprising as outcome indicators are riskier for the provider and more costly to monitor for the purchaser.

About $15 \%$ of contract negotiations are led by an agency representing the purchaser. $15 \%$ of providers have teaching status, $12 \%$ have specialist status and $53 \%$ are Foundation Trusts. The mean length of waiting time is about five weeks with a maximum of ten weeks.

Table 3: Description of the variables in the empirical models

\begin{tabular}{|c|c|c|c|c|c|}
\hline Variable & Obs. & Mean & Std. de. & Min. & Max. \\
\hline \multicolumn{6}{|l|}{ CQUIN contract complexity: } \\
\hline$\overline{\text { Number of local topics }}$ & 153 & 5.46 & 3.88 & 0.00 & 18.00 \\
\hline Number of local outcome indicators & 153 & 2.75 & 4.25 & 0.00 & 24.00 \\
\hline Number of local process indicators & 153 & 5.42 & 5.74 & 0.00 & 27.00 \\
\hline \multicolumn{6}{|l|}{ Independent variables: } \\
\hline Number of region topics & 153 & 3.73 & 3.13 & 0.00 & 13.00 \\
\hline Number of region process indicators & 153 & 2.87 & 3.27 & 0.00 & 18.00 \\
\hline Number of region outcome indicators & 153 & 2.31 & 3.83 & 0.00 & 15.00 \\
\hline Specialist Trust & 153 & 0.12 & 0.33 & 0.00 & 1.00 \\
\hline Teaching Trust & 153 & 0.15 & 0.36 & 0.00 & 1.00 \\
\hline Foundation Trust & 153 & 0.53 & 0.50 & 0.00 & 1.00 \\
\hline Provider's CQC finance score & 153 & 0.18 & 0.38 & 0.00 & 1.00 \\
\hline Provider's CQC quality score & 153 & 0.29 & 0.45 & 0.00 & 1.00 \\
\hline Mean length of waiting time in weeks & 153 & 5.40 & 1.25 & 0.93 & 9.64 \\
\hline Reference cost index (average $=100)$ & 153 & 100.77 & 9.16 & 80.00 & 157.00 \\
\hline Share of provider expenditure from lead purchaser & 153 & 0.59 & 0.27 & 0.00 & 0.99 \\
\hline Volume of patients treated $(100,000 \mathrm{~s})$ & 153 & 0.98 & 0.54 & 0.04 & 2.79 \\
\hline Share of purchaser expenditure at this provider & 153 & 0.46 & 0.30 & 0.00 & 0.96 \\
\hline Contract negotiated by an agency for the purchaser & 153 & 0.15 & 0.36 & 0.00 & 1.00 \\
\hline Rating of purchaser's financial governance & 153 & 0.71 & 0.21 & 0.00 & 1.00 \\
\hline Purchaser's percentage DFT & 153 & 4.86 & 5.52 & -7.4 & 21.3 \\
\hline Purchaser's population health & 153 & 62.71 & 3.10 & 55.8 & 68.1 \\
\hline
\end{tabular}

\footnotetext{
${ }^{14}$ These are all the contracts available on the NHS Institute for Innovation and Improvement website (see NHS).
} 


\subsection{Results}

The regression results are shown in Tables 4 and 5. They provide empirical evidence for the predictions of the theoretical model.

Table 4 displays the results for the number of locally negotiated topics using the GLM Poisson models ${ }^{15}$.

Table 4: Generalised Poisson models for number of local topics

\begin{tabular}{|c|c|c|}
\hline & Model I & Model II \\
\hline No. of region topics & $0.99(-0.04)$ & - \\
\hline Contract negotiated by an agency for purchaser & $0.78(-1.13)$ & - \\
\hline Share of purchaser expenditure at this provider & $0.70(-1.19)$ & - \\
\hline Rate of purchaser's financial governance & $1.24(0.67)$ & - \\
\hline Purchaser's DFT & $0.97^{* *}(-2.00)$ & $0.97 * * *(-2.92)$ \\
\hline Purchaser's population health & $0.93^{* * *}(-3.23)$ & $0.93^{* * *}(-4.15)$ \\
\hline Volume of patients treated $(10,000 \mathrm{~s})$ & $1.02(0.11)$ & - \\
\hline Teaching Trust & $1.31(1.63)$ & $1.35^{* *}(2.20)$ \\
\hline Specialist Trust & $0.79(-0.92)$ & - \\
\hline Foundation Trust & $0.92(-0.60)$ & - \\
\hline Provider's CQC finance score ${ }^{\dagger}$ & $1.09(0.51)$ & - \\
\hline Provider's CQC quality score ${ }^{\dagger}$ & $0.87(-1.03)$ & - \\
\hline Mean length of waiting time & $1.02(0.45)$ & - \\
\hline Reference cost index & $1.01(1.23)$ & - \\
\hline Share of provider expenditure from lead purchaser & $1.11(0.36)$ & - \\
\hline Constant & $193.42^{* * *}(3.88)$ & $375.70 * * *(5.74)$ \\
\hline N. observations & 153 & 153 \\
\hline Akaike Information Criterion & 5.61 & 5.54 \\
\hline
\end{tabular}

We find that Trusts with higher economies of scope have approximately a rate of locally negotiated topics 1.35 times greater than Trusts with lower economies of scope.

Purchasers less concerned about quality that are under-funded compared to their need and have better population health negotiate with the provider simpler contracts with fewer topics.

Table 5 shows the results for the type of locally negotiated indicators (either be outcome or process indicators). We report the results of negative binomial models as the likelihood-ratio tests do not reject over-dispersion ${ }^{16}$.

\footnotetext{
${ }^{15}$ We have also estimated the models with a negative binomial regression and the results are not very different. These results are reported in Appendix B.

${ }^{16}$ As the results of the GLM Poisson models are not dissimilar, we report them in Appendix B.
} 
Table 5: Negative Binomial models for outcome and process indicators

\begin{tabular}{|c|c|c|c|c|}
\hline & \multicolumn{2}{|c|}{ (1) N. outcome indicators } & (I) ${ }^{\text {(2) N.proc }}$ & $\begin{array}{l}\text { ss indicators } \\
\text { (II) }\end{array}$ \\
\hline Regional content ${ }^{\ddagger}$ & $1.14^{* * *}(3.01)$ & $1.15^{* * *}(3.11)$ & $1.02(0.63)$ & $1.03(0.92)$ \\
\hline $\begin{array}{l}\text { Contract negotiated } \\
\text { by an agency for purchaser }\end{array}$ & $1.33(0.66)$ & $1.45(0.90)$ & $0.41^{* * *}(-2.63)$ & $0.45^{* *}(-2.35)$ \\
\hline $\begin{array}{l}\text { Share of purchaser } \\
\text { expenditure at this provider }\end{array}$ & $0.96(-0.06)$ & - & $0.62(-1.20)$ & - \\
\hline $\begin{array}{l}\text { Rate of purchaser's } \\
\text { financial governance }\end{array}$ & $1.35(0.44)$ & $1.24(0.34)$ & $2.88^{*}(1.68)$ & $2.72(1.59)$ \\
\hline Purchaser's DFT & $0.95^{*}(-1.69)$ & $0.95 *(-1.73)$ & $0.97(-1.40)$ & $0.96^{*}(-1.86)$ \\
\hline $\begin{array}{l}\text { Purchaser's population health } \\
\text { expectancy }\end{array}$ & $0.88^{* * *}(-2.60)$ & $0.88^{* *}(-2.57)$ & $0.95(-1.44)$ & $0.96(-1.15)$ \\
\hline $\begin{array}{l}\text { Volume of patients treated } \\
(10,000 \mathrm{~s})\end{array}$ & $0.98(-0.06)$ & - & $1.31(1.42)$ & - \\
\hline Teaching Trust & $0.79(-0.85)$ & $0.78(-1.01)$ & $1.47^{*}(1.84)$ & $\left.1.70^{* *}(2.51)\right)$ \\
\hline Specialist Trust & $2.80^{* *}(2.48)$ & $2.83^{* * *}(3.05)$ & $1.06(0.16)$ & $1.08(0.26)$ \\
\hline Foundation Trust & $0.82(-0.86)$ & - & $0.93(-0.38)$ & - \\
\hline Provider's CQC finance score ${ }^{\dagger}$ & $1.21(0.71)$ & - & $1.03(0.14)$ & - \\
\hline Provider's CQC quality score ${ }^{\dagger}$ & $0.96(-0.17)$ & $1.10(0.48)$ & $0.72 *(-1.94)$ & $0.77(-1.62)$ \\
\hline Mean length of waiting time & $1.01(0.12)$ & - & $1.02(0.24)$ & - \\
\hline Reference cost index & $1.01(0.60)$ & - & $1.00(0.37)$ & - \\
\hline $\begin{array}{l}\text { Share of provider expenditure } \\
\text { from lead purchaser }\end{array}$ & $2.70(1.45)$ & $2.61^{*}(1.75)$ & $1.34(0.80)$ & $0.97(-0.10)$ \\
\hline Constant & $1015.6^{*}(1.93)$ & $1587.3^{* *}(2.32)$ & $34.43(1.26)$ & $31.87(1.38)$ \\
\hline N. observations & 153 & 153 & 153 & 153 \\
\hline Wald $\chi^{2}$ & 44.62 & 40.59 & 66.84 & 51.47 \\
\hline $\begin{array}{l}\text { Likelihood-ratio test of } \\
\text { over-dispersion }\end{array}$ & $\begin{array}{l}\chi^{2}=176.44 \\
\text { p-value }=0.000\end{array}$ & $\begin{array}{l}\chi^{2}=193.22 \\
\text { p-value }=0.000\end{array}$ & $\begin{array}{l}\chi^{2}=229.15 \\
\text { p-value }=0.000\end{array}$ & $\begin{array}{l}\chi^{2}=238.678 \\
\text { p-value }=0.000\end{array}$ \\
\hline
\end{tabular}

We find that local purchaser respond to regional leadership in the type of quality improvement included in the contract. More specifically, purchasers in regions with more regionally-mandated outcome indicators negotiated local contracts containing more outcome indicators.

Agencies for purchasers dispose of a higher bargaining power and negotiate substantially fewer process indicators by a rate of approximately 0.41 lower than single purchasers.

Purchasers that are more distant from their targeted allocation negotiate fewer outcome and process indicators, but this result is only weakly statistically significant. Those that have a better population health negotiate fewer outcome indicators. Combining this result with the one in Table 4 and with the predictions of the theoretical model, we find that these purchasers negotiate less complex schemes with fewer topics and indicators that are not directly improving outcomes because they are less concerned about quality. 
Whilst teaching Trusts negotiate more process indicators, specialist Trusts negotiate more outcome indicators. Finally, we find that as the share of provider's expenditure from the lead purchaser, a proxy for the relative bargaining power, increases so do the number of outcome indicators. This result however is only weakly statistically significant.

Table 6 shows a summary of the significant effects of each of the covariates on the CQUIN contract complexity.

Table 6: Summary of the effects of variables on the CQUIN contract complexity

\begin{tabular}{|c|c|c|c|}
\hline Variable & $\begin{array}{l}\text { No. local } \\
\text { topics }\end{array}$ & $\begin{array}{c}\text { No. outcome } \\
\text { indicators }\end{array}$ & $\begin{array}{c}\text { No. process } \\
\text { indicators }\end{array}$ \\
\hline \multicolumn{4}{|l|}{ Number of region topics } \\
\hline \multicolumn{4}{|l|}{ Number of region process indicators } \\
\hline Number of region outcome indicators & & + & \\
\hline Specialist Trust & & + & \\
\hline Teaching Trust & + & & + \\
\hline \multicolumn{4}{|l|}{ Foundation Trust } \\
\hline \multicolumn{4}{|l|}{ Provider's CQC finance score } \\
\hline \multicolumn{4}{|l|}{ Provider's CQC quality score } \\
\hline \multicolumn{4}{|l|}{ Mean length of waiting time } \\
\hline \multicolumn{4}{|l|}{ Reference cost index } \\
\hline Share of provider expenditure from lead purchaser & & + & \\
\hline \multicolumn{4}{|l|}{ Volume of patients treated $(100,000 \mathrm{~s})$} \\
\hline \multicolumn{4}{|l|}{ Share of purchaser expenditure at this provider } \\
\hline Contract negotiated by an agency for the purchaser & & & - \\
\hline \multicolumn{4}{|l|}{ Rating of purchaser's financial governance } \\
\hline Purchaser's DFT & - & - & - \\
\hline Purchaser's population health & - & - & \\
\hline
\end{tabular}

\section{Conclusions}

Despite the creation of a centrally determined national NHS standard contract, the new reforms in 2000s introduced some flexibility in contractual arrangements between providers and purchasers/commissioners. In addition, from the mid 2000s a greater emphasis on quality of healthcare was placed on both providers and purchasers. In 2009/10 the Commissioning for Quality and Innovation (CQUIN) framework was introduced linking $0.5 \%$ of a providers contract value to quality improvement. This proportion increased to $1.5 \%$ in $2010 / 11$. The purpose of this reform was to improve quality by encouraging commissioner-provider contractual discussions to focus on quality. In practice, CQUIN brought together the contractual flexibility of the reform period 1990-1997 with a new focus on quality in the mid 2000s.

In this paper we analyse the second year of the CQUIN in which quality contracts could be designed around nationally-mandated, regionally-mandated 
or locally-agreed goals. We determine whether and which provider/purchaser characteristics are related to the choice of contract form for quality improvement. We focus on two measures of complexity of such contracts, namely the number of topics (whereas a larger number of clinical areas increase monitoring costs of the purchaser) and the type of indicators included in these topics (whereas outcome indicators are riskier than process indicators for the provider).

Whilst there is a relatively large literature on contract choice in several areas of economics such as agricultural economics, procurement, mining and oil industry, the health economics empirical literature on this topic is still scarce. Only two papers, namely Csaba and Fenn (Vol. 16, 1997) and Chalkley and McVicar (Vol. 27, 2008), have analysed the flexibility of contractual choice over volume of health services in the NHS between 1990 and 1997.

This paper can be placed within such literature exploiting the nature of the NHS reforms after the year 2000 and including a further dimension to contractual choice, namely quality improvement.

Very little research has looked at how purchasers design contracts to incentivise quality improvement (Berthiaume et al. (2004); Reiter et al. (2006); Roski et al. (2003)). No attempt has been made by these papers to provide an economic model of the adoption of a quality incentive scheme.

Within the theoretical literature, this paper can be placed in the strand of research concerned with multitasking problems and observable but not contractible quality. By designing a two-stage game with a purchaser and a provider we show that quality contracts depend on the degree of concern for quality of the purchaser, the efficiency and size of the provider, and the number of constraints placed on a contract, namely the regional content of the scheme.

We test whether purchasers behave as expected from the theoretical model in the second year of the scheme using count data models on the number of locally negotiated topics and the number of outcome and process indicators. We find that agencies prefer lower monitoring costs negotiating fewer process indicators. Under-resourced purchasers appear to have set more complex contracts in the hope that providers would fail and they would have to pay out less. Purchasers with healthier population have set less complex CQUIN schemes. Finally, we find that local purchasers respond to regional leadership in the type of quality improvement included in the contract and that teaching Trusts tend to negotiate more complex contract with a larger number of topics, but also with a larger number of process indicators. 
Our paper makes a number of contributions to the literature on contract choice. Firstly, by exploiting the characteristics of the CQUIN scheme we are able to observe the quality element of the contract directly rather than volume of services. Secondly, we dispose of larger information with regard to provider/purchaser characteristics compared to the two previous studies in health economics. Finally, we develop a game-theoretic approach that considers contractual choice of quality dimensions and we directly test the empirical implications of such a model.

\section{Acknowledgements}

This research was funded by a grant from the Department of Health Policy Research Programme. The views expressed are the sole responsibility of the authors.

\section{Appendix A. Derivation of the theoretical model}

(I) Comparative statics, $\beta \in(0,1)$

The interior solution is given by the simultaneous satisfaction of the following conditions

$$
\begin{aligned}
& 0=F(n ; \cdot) \\
& 0=G(n ; \cdot)
\end{aligned}
$$

The total differentiation of the system produces:

$$
\begin{aligned}
& 0=d n F_{n}^{\prime}+d R F_{R}^{\prime}+d \alpha F_{\alpha}^{\prime}+d \delta F_{\delta}^{\prime}+d \beta F_{\delta}^{\prime}+d \vartheta F_{\vartheta}^{\prime}+d q_{0} F_{q_{0}}^{\prime}+ \\
& +d R_{0} F_{R_{0}}^{\prime}+d x F_{x}^{\prime}+d p F_{p}^{\prime}+d k F_{k}^{\prime} \\
& 0=d n G_{n}^{\prime}+d R G_{R}^{\prime}+d \alpha G_{\alpha}^{\prime}+d \delta G_{\delta}^{\prime}+d \beta G_{\delta}^{\prime}+d \vartheta G_{\vartheta}^{\prime}+d q_{0} G_{q_{0}}^{\prime}+ \\
& +d R_{0} G_{R_{0}}^{\prime}+d x G_{x}^{\prime}+d p G_{p}^{\prime}+d k G_{k}^{\prime}
\end{aligned}
$$

Notice that $F_{k}^{\prime}=G_{k}^{\prime}=F_{\beta}^{\prime}=0, F_{R}^{\prime}=F_{R_{0}}^{\prime}=U_{n}^{\prime} g^{\prime \prime}<0$ and $G_{R}^{\prime}=G_{R_{0}}^{\prime}=$ 


$$
\begin{aligned}
\beta(1-\beta) V^{\beta-1} U^{1-\beta}(-1 & \left.-\frac{g^{\prime \prime}}{1-\beta}-\frac{\left(g^{\prime}\right)^{2}}{V}-2 \frac{g^{\prime}}{U}\right)<0 . \text { In addition: } \\
F_{n}^{\prime} & =V_{n}^{\prime \prime}+U_{n}^{\prime \prime} g^{\prime}<0 \\
F_{\alpha}^{\prime} & =B_{n}^{\prime}>0 \\
F_{\beta}^{\prime} & =0 \\
F_{\delta}^{\prime} & =B_{n}^{\prime} g^{\prime}>0 \\
F_{\vartheta}^{\prime} & =-c_{n}^{\prime} g^{\prime}<0 \\
F_{q_{0}}^{\prime} & =\alpha B_{n q_{0}}+g^{\prime}\left(\delta B_{n q_{0}}^{\prime \prime}-\vartheta c_{n q_{0}}^{\prime \prime}\right) \\
F_{x}^{\prime} & =\alpha B_{n x}+g^{\prime}\left(\delta B_{n x}^{\prime \prime}-\vartheta c_{n x}^{\prime \prime}\right)+U_{n}^{\prime} g^{\prime \prime} p \\
F_{p}^{\prime} & =U_{n} g^{\prime \prime} x<0
\end{aligned}
$$

and

$$
\begin{aligned}
& G_{n}^{\prime}=\beta(\beta-1) V^{\beta-2} U^{1-\beta}\left[V_{n}^{\prime}\left(\frac{V}{U}+g^{\prime}\right)-U_{n}^{\prime} \frac{V}{U}\left(\frac{V}{U}+g^{\prime}\right)\right]>0 \\
& G_{\alpha}^{\prime}=\beta(1-\beta) B V^{\beta-2} U^{1-\beta}\left(g^{\prime}+\frac{V}{U}\right)>0 \\
& G_{\beta}^{\prime}=-g^{\prime} V^{\beta-1} U^{1-\beta}[1+\beta \log (V / U)]+V^{\beta} U^{-\beta}[(1-\beta) \log (V / U)-1]<0 \\
& G_{\delta}^{\prime}=\beta(1-\beta) B V^{\beta-1} U^{-\beta}\left(-g^{\prime}-\frac{V}{U}\right)<0 \\
& G_{\vartheta}^{\prime}=\beta(1-\beta) c V^{\beta-1} U^{-\beta}\left(g^{\prime}+\frac{V}{U}\right)>0 \\
& G_{q_{0}}^{\prime}=\beta(1-\beta)\left(\alpha B_{q_{0}}^{\prime}-\frac{V}{U}\left(\delta B_{q_{0}}^{\prime}-\vartheta c_{q_{0}}^{\prime}\right)\right) V^{\beta-2} U^{1-\beta}\left(g^{\prime}+\frac{V}{U}\right) \\
& G_{x}^{\prime}=\beta(1-\beta) B V^{\beta-2} U^{1-\beta}\left[-\frac{g^{\prime \prime} p}{1-\beta}+\left(g^{\prime}+\frac{V}{U}\right)\left(\alpha B_{x}^{\prime}-g^{\prime} p-\frac{V}{U}\left(p+\delta B_{x}^{\prime}-\vartheta c_{x}^{\prime}\right)\right)\right] \\
& G_{p}^{\prime}=\beta(1-\beta) V^{\beta-1} U^{1-\beta}\left(-\frac{g^{\prime \prime} x}{1-\beta}-\left(g^{\prime}\right)^{2}-2 \frac{g^{\prime}}{U}-\frac{V}{U}\right)<0
\end{aligned}
$$

It follows that $\frac{d n}{d z}$, where $z$ represents any of the exogenous parameters in the model, is given by $\frac{d n}{d z}=\frac{-F_{z}^{\prime} G_{R}^{\prime}+G_{z}^{\prime} F_{R}^{\prime}}{A}$, where $A=F_{n}^{\prime} G_{R}^{\prime}-G_{n}^{\prime} F_{R}^{\prime}>0$. The signs reported in the main text follow.

(II)Comparative statics, $\beta=0$

The solution of the bargaining problem when $\beta=0 \lambda_{2}, \lambda 1>0$ (and $n>0$, 
$R>0$ ) is given by the simultaneous satisfaction of the following conditions.

$$
\begin{aligned}
& 0=k p x-R-R_{0} \\
& 0=U_{n}^{\prime}
\end{aligned}
$$

Totally differentiating the two conditions and solving the system we obtain

$$
\begin{aligned}
& \frac{d n}{d \alpha}=0=\frac{d n}{d R_{0}}=\frac{d n}{d k}=\frac{d n}{d p} \\
& \frac{d n}{d \delta}=-\frac{B_{n}^{\prime}}{C}>0 \\
& \frac{d n}{d \vartheta}=\frac{c_{n}^{\prime}}{C}<0 \\
& \frac{d n}{d q_{0}}=-\frac{\delta B_{n q_{0}}^{\prime \prime}-\vartheta c_{n q_{0}}^{\prime \prime}}{C} \\
& \frac{d n}{d x}=-\frac{\delta B_{n x}^{\prime \prime}-\vartheta c_{n x}^{\prime \prime}}{C} \\
& C=U_{n}^{\prime \prime}<0
\end{aligned}
$$

(III) Comparative statics, $\beta=1$

$$
\begin{aligned}
& 0=-\lambda_{2} \vartheta c_{n}^{\prime} \\
& 0=p x+R+R_{0}-\vartheta c
\end{aligned}
$$

Totally differentiating the two conditions and solving the system we obtain

$$
\begin{aligned}
& \frac{d n}{d \alpha}=0=\frac{d n}{d R_{0}}=\frac{d n}{d k}=\frac{d n}{d p}=\frac{d n}{d \delta}=0 \\
& \frac{d n}{d \vartheta}=\frac{\lambda_{2} c_{n^{\prime}}}{D}<0 \\
& \frac{d n}{d q_{0}}=\frac{\lambda_{2} \vartheta c_{n q_{0}^{\prime \prime}}}{D} \\
& \frac{d n}{d x}=\frac{\lambda_{2} \vartheta c_{n x^{\prime \prime}}}{D} \\
& D=-\lambda_{2} \vartheta c_{n}^{\prime \prime}<0
\end{aligned}
$$




\section{Appendix B. Additional results and figures}

Table B.1: Negative Binomial models for number of local topics

\begin{tabular}{lll}
\hline & Model I & Model II \\
\hline No. region topics & $1.00(0.11)$ & - \\
Contract negotiated by an agency for purchaser & $0.81(-0.80)$ & - \\
Share of purchaser expenditure at this provider & $0.72(-1.10)$ & - \\
Rate of purchaser's financial governance & $1.24(0.56)$ & - \\
Purchaser's DFT & $0.96^{* *}(-2.17)$ & $0.97^{* * *}(-3.09)$ \\
Purchaser's population health & $0.94^{* * *}(-2.71)$ & $0.94^{* * *}(-3.27)$ \\
Volume of patients treated in $2009 / 10(10,000 s)$ & - & - \\
Teaching Trust & $1.27^{*}(1.79)$ & $1.32^{* *}(2.38)$ \\
Specialist Trust & $0.77(-1.16)$ & - \\
Foundation Trust & $0.92(-0.66)$ & - \\
Provider's CQC finance score ${ }^{\dagger}$ & $1.08(0.40)$ & - \\
Provider's CQC quality score ${ }^{\dagger}$ & $0.85(-1.27)$ & - \\
Mean length of waiting time & $1.03(0.61)$ & - \\
Reference cost index & $1.01^{*}(1.89)$ & - \\
Share of provider expenditure from lead purchaser & $1.11(0.33)$ & - \\
Constant & $90.58^{* *}(2.35)$ & $334.87^{* * *}(4.53)$ \\
\hline N. observations & 153 & 153 \\
Wald $\chi^{2}$ & 66.89 & 33.81 \\
Likelihood-ratio test of over-dispersion & $\chi^{2}=50.48$ & $\chi^{2}=54.49$ \\
& p-value=0.000 & p-value=0.000 \\
\hline Incidence Rate Ratios displayed. z-stats in () scaled using std. errors corrected for over-dispersion \\
using square root of Pearson $\chi^{2}$-dispersion. ${ }^{\dagger}$ Fair/weak compared to good/excellent. ${ }^{* * *} p<0.01 ;$ \\
$*^{* *} p<0.05$. & &
\end{tabular}


Table B.2: Generalised Poisson models for outcome and process indicators

\begin{tabular}{|c|c|c|c|c|}
\hline & \multicolumn{2}{|c|}{ (1) N. outcome indicators } & \multicolumn{2}{|c|}{ (2) N. process indicators } \\
\hline & (I) & $(I I)$ & (I) & (II) \\
\hline Regional content $^{\ddagger}$ & $1.13^{* * *}(3.69)$ & $1.13^{* * *}(4.00)$ & $1.01(0.47)$ & $1.02(0.88)$ \\
\hline $\begin{array}{l}\text { Contract negotiated } \\
\text { by an agency for purchaser }\end{array}$ & $1.13(0.33)$ & $1.39(0.99)$ & $0.39 * *(-2.67)$ & $0.43^{* *}(-2.46)$ \\
\hline $\begin{array}{l}\text { Share of purchaser } \\
\text { expenditure at this provider }\end{array}$ & $0.60(-0.85)$ & - & $0.62(-1.18)$ & - \\
\hline $\begin{array}{l}\text { Rate of purchaser's } \\
\text { financial governance }\end{array}$ & $1.69(0.84)$ & $1.45(0.64)$ & $1.92(1.47)$ & $1.84(1.46)$ \\
\hline Purchaser's DFT & $0.96(-1.54)$ & $0.96(-1.55)$ & $0.97(-1.36)$ & $0.96^{*}(-1.83)$ \\
\hline $\begin{array}{l}\text { Purchaser's population health } \\
\text { expectancy }\end{array}$ & $0.88^{* * *}(-3.44)$ & $0.89 * * *(-3.32)$ & $0.93^{* * *}(-2.61)$ & $0.94^{* *}(-2.32)$ \\
\hline $\begin{array}{l}\text { Volume of patients treated } \\
\text { in } 2009 / 10(10,000 \mathrm{~s})\end{array}$ & $1.20(0.58)$ & - & $1.30(1.23)$ & - \\
\hline Teaching Trust & $0.85(-0.49)$ & $-0.83(-0.65)$ & $1.66^{* *}(2.30)$ & $1.83^{* * *}(3.26)$ \\
\hline Specialist Trust & $2.89 * *(2.38)$ & $2.99^{* * *}(3.31)$ & $1.41(1.06)$ & $1.28(0.99)$ \\
\hline Foundation Trust & $0.78(-0.93)$ & - & $0.90(-0.60)$ & - \\
\hline Provider's CQC finance score ${ }^{\dagger}$ & $1.43(1.16)$ & - & $1.06(0.22)$ & - \\
\hline Provider's CQC quality score ${ }^{\dagger}$ & $0.93(-0.29)$ & $1.10(0.42)$ & $0.84(-0.92)$ & $0.89(-0.65)$ \\
\hline Mean length of waiting time & $0.95(-0.68)$ & - & $1.01(0.17)$ & - \\
\hline Reference cost index & $1.00(0.17)$ & - & $0.99(-0.40)$ & - \\
\hline $\begin{array}{l}\text { Share of provider expenditure } \\
\text { from lead purchaser }\end{array}$ & $2.38(1.57)$ & $1.99(1.37)$ & $1.44(0.94)$ & $1.03(0.10)$ \\
\hline Constant & $2362.6^{* * *}(2.60)$ & $1298.5^{* * *}(2.97)$ & $342.5^{* *}(2.57)$ & $138.7 * * *(2.78)$ \\
\hline N. observations & 153 & 153 & 153 & 153 \\
\hline Akaike Information Criterion & 5.38 & 5.41 & 6.97 & 6.97 \\
\hline
\end{tabular}


Figure B.2: Number of local topics

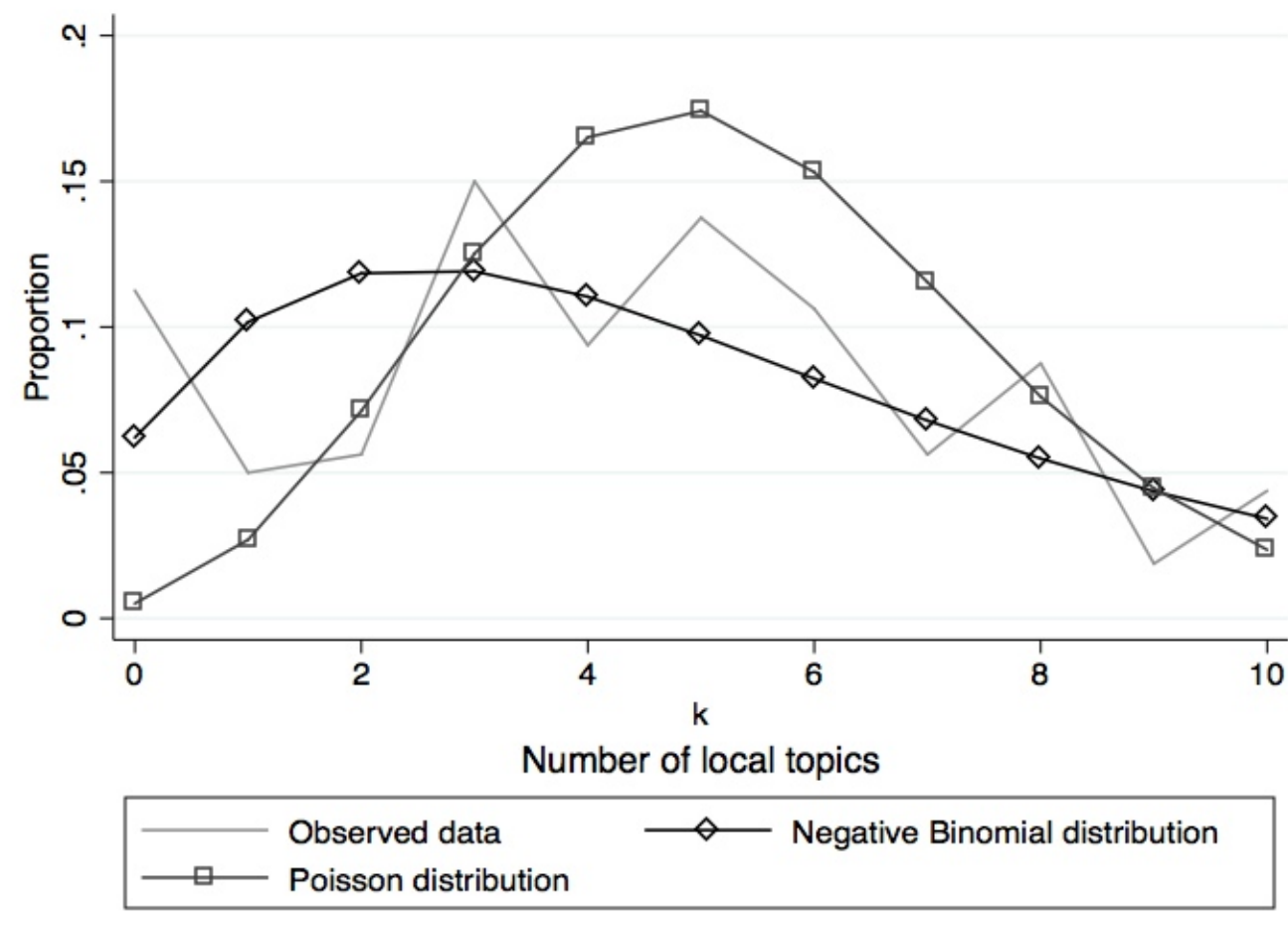


Figure B.3: Number of local outcome indicators

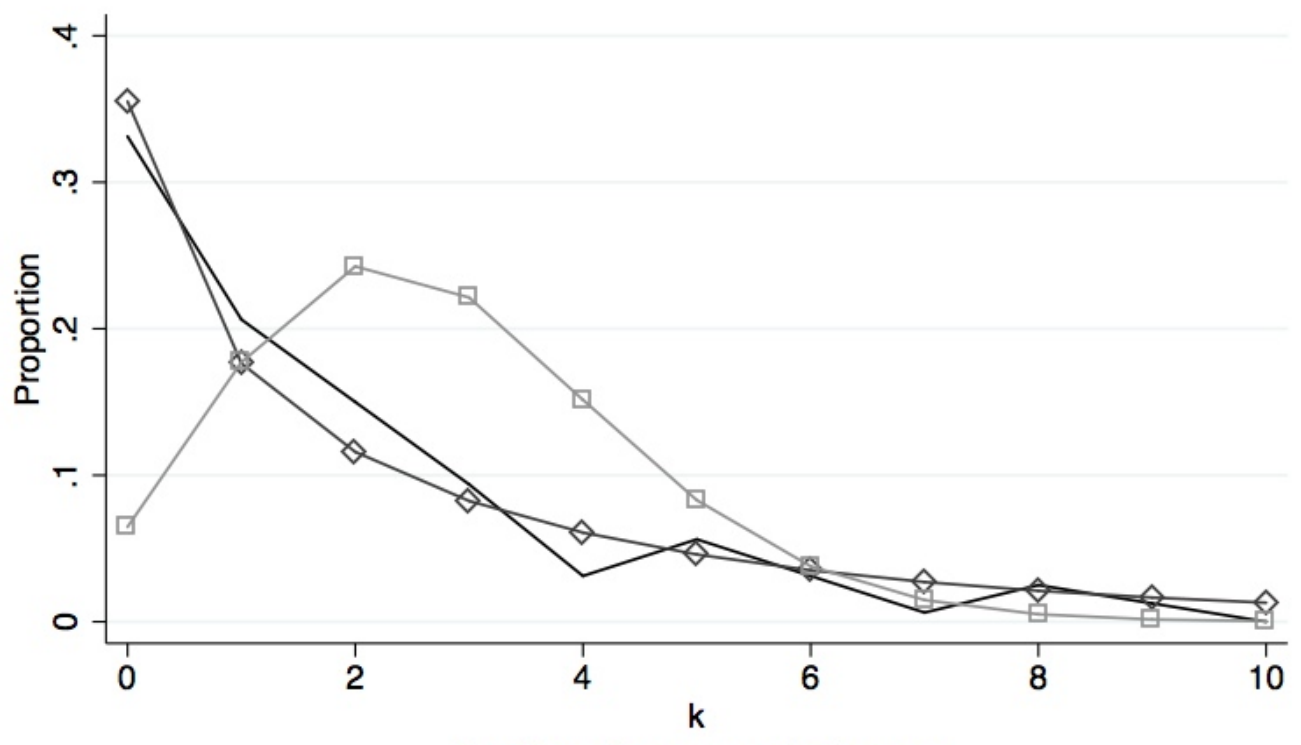

Number of outcome indicators

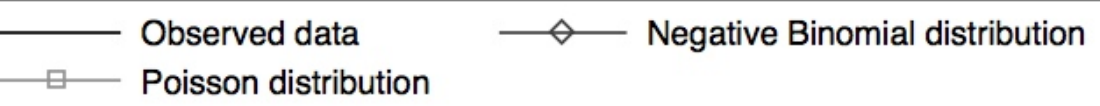


Figure B.4: Number of local process indicators

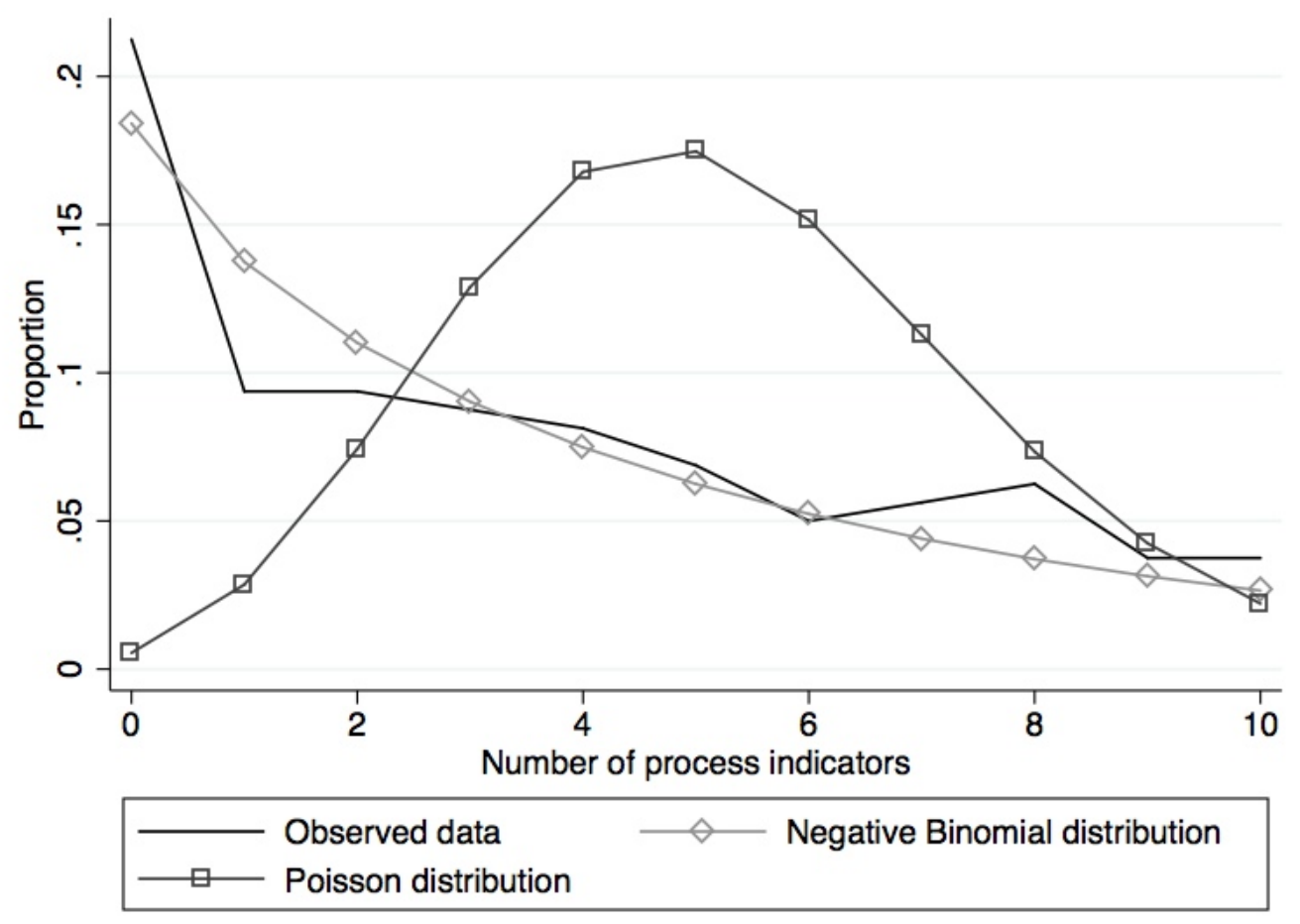




\section{References}

Barros, P.P., Martinez-Giralt, X., 2008. Selecting health care providers: \&quot;any willing provider\&quot; vs. negotiation. European Journal of Political Economy 24, 402-414.

Barros, P.P., Martinez-Giralt, X., 2011. Health Economics. An Industrial Organization Perspective. Routledge.

Berthiaume, J.T., Tyler, P., Ng-Osorio, J., LaBresh, K., 2004. Aligning financial incentives with "get with the guidelined" to improve cardiovascular care. American Journal of Managed Care 10, 501-504.

Brekke, K.R., Nuscheler, R., Straume, O.R., 2006. Quality and location choices under price regulation. Journal of Economics \& Management Strategy $15,207-227$.

Brekke, K.R., Nuscheler, R., Straume, O.R., 2007. Gatekeeping in health care. Journal of Health Economics 26, 149-170.

Calem, P., Rizzo, J., 1995. Competition and specialization in the hospital industry: An application of hotelling's location model. Southern Economic Journal 61, 1182-1198.

Cameron, A.C., Trivedi, P.K., 1998. Regression Analysis of Count Data. Number 9780521635677 in Cambridge Books, Cambridge University Press.

Chalkley, M., Malcomson, J.M., 2000. Government purchasing of health services, in: Culyer, A.J., Newhouse, J.P. (Eds.), Handbook of Health Economics. Elsevier. volume 1 of Handbook of Health Economics. chapter 15, pp. 847-890.

Chalkley, M., McVicar, D., Vol. 27, 2008. Choice of contracts in the british national health service: An empirical study. Journal of Health Economics 27, $1155-1167$.

Coase, R.H., 1937. The nature of the firm. Economica NS4, 386-405.

Corts, K., Singh, J., 2004. The effect of repeated interaction on contract choice: evidence from offshore drilling. Journal of Law, Economics and Organization 20, 230-260. 
CQC, C.Q.C., 2005-2009. Reports on quality of financial management.

Csaba, I., Fenn, P., Vol. 16, 1997. Contractual choice in the managed health care market an empirical analysis. Journal of Health Economics 16, 579588 .

Department of Health, 2002. Delivering the nhs plan: Next steps on investment, next steps on reforms.

Department of Health, 2009. Using the commissioning for quality and innovation (cquin) payment framework: For the nhs in england 2009/10.

Eggleston, K., 2005. Multitasking and mixed systems for provider payment. Journal of Health Economics 24, 211-223.

Elliott, R., Sutton, M., Ma, A., McConnachie, A., Morris, S., Rice, N., Skatun, D., 2009. The role of the mff in distributing nhs funding: taking account of differences in local labour market conditions. Health Economics $19(5), 532-548$.

Farrar, S., Yi, D., Sutton, M., Chalkley, M., Sussex, J., Scott, A., 2009. Has payment by results affected the way that english hospitals provide care? difference-in-differences analysis. BMJ 339.

Gravelle, H., Sutton, M., Morris, S., Windmeijer, F., Leyland, A., Dibben, C., Muirhead, M., 2003. Modelling supply and demand influences on the use of health care: implications for deriving a needs-based capitation formula. Health Economics 12, 985-1004.

Hess, J., 1983. The Economics of Organization. Amsterdam.

Holmstrom, B., Milgrom, P., 1991. Multitask principal-agent analyses: Incentive contracts, asset ownership, and job design. Journal of Law, Economics and Organization 7, 24-52.

Joskow, P.L., 1987. Contract duration and relationship-specific investments: Empirical evidence from coal markets. American Economic Review 77, 168-85.

Kaarbe, O.M., Siciliani, L., 2011. Multitasking, Quality and Pay for Performance. Working Papers in Economics 07/08. University of Bergen, Department of Economics. 
Maddala, G.S., 1986. Limited Dependent and Qualitative Variables in Econometrics. Number 9780521338257 in Cambridge Books, Cambridge University Press.

Mayer, T., 1960. The distribution of ability and earnings. Review of Economics and Statistics 52, 189-195.

NHS, I., . Nhs institute for innovation and improvement.

Petsoulas, C., Allen, P., Hughes, D., Vincent-Jones, P., Roberts, J., 2011. The use of standard contracts in the english national health service: A case study analysis. Social Science \& Medicine 73, 185-192.

Reiter, K., Nahra, T., Alexander, J., Hweeler, J.R., 2006. Hospital responses to pay-for-performance incentives. Health Services Management Research 19, 123-124.

Roski, J., Jeddeloh, R., An, L., Lando, H., Hannan, P., Hall, C., Zhu, S., 2003. The impact of financial incentives and a patient registry on preventive care quality: increasing provider adherence to evidence-based smoking cessation practice guidelines. Preventive Medicine 36, 291-299.

Sayyad, G.M.E., 1973. Bayesian and classical analysis of poisson regression. Journal of the Royal Statistics Society Series B 35, 445-451.

Shaban, R., 1987. testing between competing models of sharecropping. Journal of Political Economy 95, 893-920.

Shepard, A., 1993. Contractual form, retail price, and asset characteristics in gasoline retailing. RAND Journal of Economics 24, 58-77.

Siciliani, L., Stanciol, A., 2008. Bargaining and the Provision of Health Services. Discussion Papers 08/28. Department of Economics, University of York.

Simon, H., 1951. A formal theory of the employment relationship. Econometrica 19, 293-305.

Street, A., Maynard, A., 2007. Payment by results: qualified ambition? Health Economics, Policy and Law 2(4), 445-448.

Williamson, O., 1985. The Economic Institutions of capitalism. New York. 
Williamson, O.E., 1983. Credible commitments: Using hostages to support exchange. American Economic Review 73, 519-40.

Wooldridge, J.M., 2001. Econometric Analysis of Cross Section and Panel Data. volume 1 of MIT Press Books. The MIT Press. 